\title{
BMJ Open Impact of a social network-based intervention promoting diabetes self-management in socioeconomically deprived patients: a qualitative evaluation of the intervention strategies
}

\author{
C Vissenberg, ${ }^{1} \mathrm{~K}$ Stronks, ${ }^{1} \mathrm{G}$ Nijpels, ${ }^{2} \mathrm{P} \mathrm{J}$ M Uitewaal, ${ }^{3} \mathrm{~B} \mathrm{~J} \mathrm{C}$ Middelkoop, ${ }^{4}$ \\ M J E Kohinor, ${ }^{1}$ M A Hartman, ${ }^{1}{ }^{V}$ Nierkens ${ }^{1}$
}

To cite: Vissenberg C, Stronks K, Nijpels G, et al. Impact of a social networkbased intervention promoting diabetes self-management in socioeconomically deprived patients: a qualitative evaluation of the intervention strategies. BMJ Open 2016;6: e010254. doi:10.1136/ bmjopen-2015-010254

- Prepublication history and additional material is available. To view please visit the journal (http://dx.doi.org/ 10.1136/bmjopen-2015010254).

Received 13 October 2015 Revised 22 January 2016 Accepted 25 January 2016

CrossMark

For numbered affiliations see end of article.

Correspondence to Dr Charlotte Vissenberg; c.vissenberg@amc.uva.nl

\section{ABSTRACT}

Objective: There is a need for effective interventions that improve diabetes self-management (DSM) among socioeconomically deprived patients with type 2 diabetes. The group-based intervention Powerful Together with Diabetes (PTWD) aimed to increase social support for DSM and decrease social influences hindering DSM (eg, peer pressure, social norms) in patients living in deprived neighbourhoods. Through a qualitative process evaluation, this paper aims to study whether this intervention changed social support and social influences, and which elements of the intervention contributed to this.

Methods: The intervention group (IG) was compared with a standard group-based educational intervention (control group, CG). 27 qualitative in-depth interviews with participants (multiethnic sample) and 24 interviews with group leaders were conducted. Interviews were coded and analysed using MAXQDA according to framework analysis.

Results: Patients in the IG experienced more emotional support from group members and more instrumental and appraisal support from relatives than those in the CG. Also, they were better able to recognise and cope with influences that hinder their DSM, exhibited more positive norms towards DSM and increased their priority regarding DSM and their adherence. Finally, the engagement in DSM by relatives of participants increased. Creating trust between group members, skills training, practising together and actively involving relatives through action plans contributed to these changes.

Conclusions: A group-based intervention aimed at creating trust, practising together and involving relatives has the potential to increase social support and diminish social influences hindering DSM in socioeconomically deprived patients with diabetes. Promising elements of the intervention were skills training and providing feedback using role-playing exercises in group sessions with patients, as well as the involvement of patients' significant others in selfmanagement tasks, and actively involving them in making an action plan for self-management. These

\author{
Strengths and limitations of this study
}

By using qualitative interviews, this study provides an in-depth understanding of how this intervention influenced social support and social influences, and which intervention strategies were instrumental in this.

- Owing to its qualitative nature, this study cannot be used to determine the actual effect of changes in social support and social influences on diabetes self-management behaviour.

- The study identified a few promising elements which could be used in future interventions for socioeconomically deprived patients with type 2 diabetes.

positive results justify the value of further evaluating the effectiveness of this intervention in a larger sample. Trial registration number: NTR1886, Results.

\section{BACKGROUND}

People in lower socioeconomic groups are disproportionately affected by type 2 diabetes and also have more diabetes-related complications and higher diabetes-related mortality compared with patients in higher socioeconomic groups. ${ }^{1-3}$ A poorer glycaemic control, related to less adequate self-management behaviour, partly accounts for these increased risks. ${ }^{4}$ Properly managing type 2 diabetes requires a schedule of extensive self-management behaviours. These include frequent monitoring of blood glucose levels, balancing insulin dosages with food intake and physical activity and prevention or treatment of hypoglycaemia. Complying with and maintaining such complex health regimens seems to be challenging, especially for socioeconomically deprived patients. ${ }^{5-7}$ 
There is thus a need for effective interventions that improve glycaemic control among socioeconomically deprived patients with type 2 diabetes. Interventions that target social influences affecting self-management behaviour, such as social support, might be promising. Social interactions with friends and family members have a major impact on self-management. Social support, the aid and assistance exchanged through social relationships and interpersonal transactions, can positively influence self-management, but significant others can also hinder self-management by interfering with or paying too much attention to self-management. ${ }^{8} \quad 9$ Socioeconomically deprived patients seem to have less access to supportive social networks, generally have fewer sources of social support in their social environments and receive less social support, which is needed for adherence. ${ }^{10-12}$ In addition, they are often confronted with social influences from their immediate social environments that hinder self-management (eg, peer pressure, specific cultural beliefs and expectations and fewer positive role models). ${ }^{13} 14$

A few studies indicate the effectiveness of a social network intervention on diabetes control. ${ }^{15}{ }^{16}$ Little is known, however, about intermediate variables such as social support or social influences and the intervention strategies by which these effects can be established. In other words, which strategies should be used in social network-based interventions to actually stimulate social support in the immediate social environment and to diminish hindering social influences on self-management, especially among socioeconomically deprived patients? This knowledge is imperative to further develop this type of interventions.

Therefore, we developed a social network-based intervention (Powerful Together with Diabetes) that aimed to stimulate social support for self-management and diminish hindering social influences on self-management among socioeconomically deprived patients. The intervention consisted of a series of 24 meetings in which the patients as a group learnt about diabetes and practised these newly learnt behaviours. At the same time, their significant others received an intervention as well aimed at increasing knowledge and supporting someone with diabetes. Home visits were also conducted to make a shared action plan for the patient and their significant others.

The aim of this paper is to determine how the intervention worked. More specifically, we studied which changes in social support and social influences were experienced by participants and which of the employed intervention strategies were effective in increasing social support for self-management and diminishing social influences hindering self-management. A qualitative approach was used to explore and understand these strategies.

\section{METHODS}

The study reported here is part of the Diabetes in Social Context (DISC) study; the design of the study is described elsewhere. ${ }^{17}$ An experimental non-randomised design with an intervention and a control group was used. For the intervention to be successful, it was important that the participants lived near each other which made randomisation impossible. The intervention was compared with standard group-based diabetes education to be able to determine the additive value of actively intervening on social support, social influences and the immediate social environment of patients at the same time. The intervention group received Powerful Together with Diabetes and the control group received Know Your Sugar (see figure 1). The quasi-experimental trial was accompanied by a process evaluation that aimed to explore the mechanisms that underlay the effect of the intervention: why did it work?

The primary outcome measures of the trial were haemoglobin Alc (HbAlc) and quality of life. ${ }^{17}$ To show the effect of the intervention, power calculations showed that 128 participants had to be included in both arms. Multiple recruitment problems were encountered such as difficulties recruiting general practitioners (GPs) owing to busy works schedules, incomplete or outdated contact information in the GPs' records and eligible participants not answering their phones. Also, eligible patients indicated that they were too busy, had to look after relatives, did not want to improve their selfmanagement or did not want to participate in a group. Therefore, at the beginning of the intervention, we were only able to recruit half of the required numbers. As a consequence, the effect of the intervention on quality of life and HbAlc could not be studied. This paper reports on the data of the process evaluation regarding the intervention mechanisms.

Patients who met the following criteria were selected from the patient records of GPs: having type 2 diabetes, diagnosed for at least 1 year, older than 35 , glycated haemoglobin (HbAlc) higher than $53 \mathrm{mmol} / \mathrm{mol}$ $(7.0 \%)$ and living in a socioeconomically deprived neighbourhood according to an official ranking of the Dutch government. These neighbourhoods are characterised by living conditions that are of lower quality than those in other neighbourhoods due to a cumulation of problems. These problems consist of high unemployment rates, low income, high criminality, degradation, feelings of unsafety, a lack of relevant social networks and social contacts. ${ }^{18}$ Patients with severe psychiatric disorders and those who were unable to come to the intervention location, or planned to stay abroad for longer than 6 weeks were excluded. The intervention and control groups were matched on gender, ethnicity and organisation of diabetes care.

Powerful Together with Diabetes and Know Your Sugar were group-based interventions, with 7-10 participants per group. Ten intervention groups with a total of 69 patients participated in Powerful Together with Diabetes. Nine control groups with a total of 62 patients participated in Know Your Sugar (see table 1). 


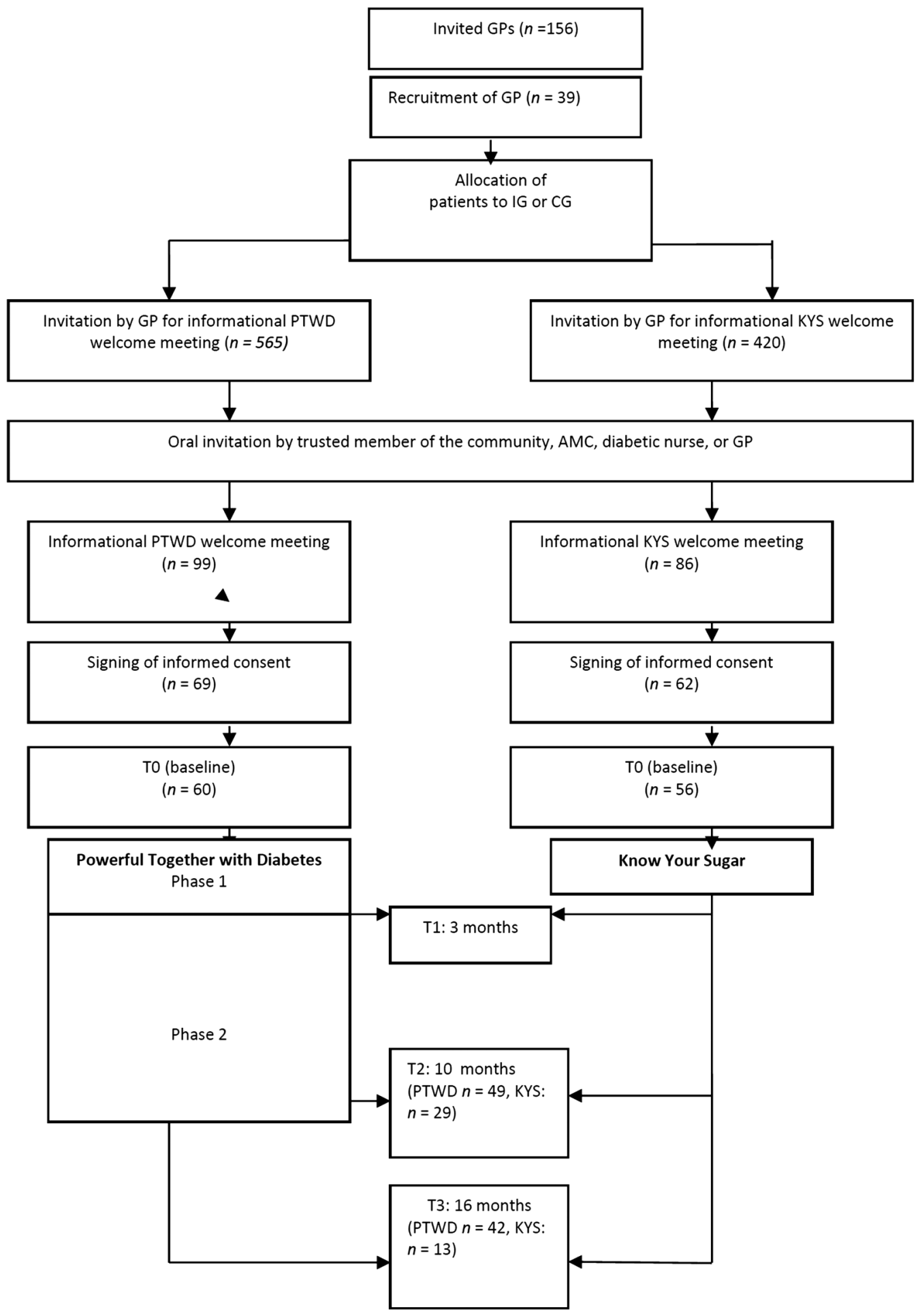

Figure 1 Overview of the flow of the DISC study. DISC, Diabetes in Social Context study; GP, general practitioner; IG, intervention group; CG, control group; PTWD, Powerful Together with Diabetes intervention; KYS, Know Your Sugar intervention.

\section{THE INTERVENTION (POWERFUL TOGETHER WITH} DIABETES) AND CONTROL (KNOW YOUR SUGAR) GROUPS In short, Powerful Together with Diabetes lasted 10 months and consisted of 24 group meetings for the participants, 6 sessions for their significant others (relatives or friends) and 2 social network therapy sessions at home in which participants and their significant others were present. ${ }^{17}$ Significant others were selected and invited by the participants with a maximum of two persons per participant. The participants were asked to invite someone who was important with regard to their diabetes self-management. The intervention objectives were to get the participants to support and positively influence each other to better manage their diabetes 
Table 1 Characteristics of respondents in the DISC study and the process evaluation

\begin{tabular}{|c|c|c|c|c|}
\hline & \multicolumn{2}{|c|}{ Quasi-experimental trial $(n=131)$} & \multicolumn{2}{|c|}{$\begin{array}{l}\text { Qualitative process evaluation } \\
(n=27)\end{array}$} \\
\hline & $\begin{array}{l}\text { Intervention } \\
\text { group }(n=69)\end{array}$ & $\begin{array}{l}\text { Control } \\
\text { group }(n=62)\end{array}$ & $\begin{array}{l}\text { Intervention } \\
\text { group }(n=17)\end{array}$ & $\begin{array}{l}\text { Control } \\
\text { group }(n=10)\end{array}$ \\
\hline Age (SD) & $61.15(10.4)$ & $62.3(9.9)$ & $60.5(7.86)$ & $62.9(10.94)$ \\
\hline \multicolumn{5}{|l|}{ Gender } \\
\hline Female (\%) & 66.1 & 69.8 & 73.3 & 77.8 \\
\hline \multicolumn{5}{|l|}{ Total household income per month (\%) } \\
\hline$€ 454-€ 1270$ & 34.8 & 46.8 & 18.8 & 30 \\
\hline$€ 1270-€ 1906$ & 30.4 & 25.8 & 37.5 & 40 \\
\hline More than $€ 1906$ & 10 & 9.7 & 31.3 & 20 \\
\hline Would rather not say & 24.6 & 17.7 & 12.5 & 10 \\
\hline \multicolumn{5}{|l|}{ Ethnicity (\%) } \\
\hline Dutch & 40.6 & 27.4 & 47 & 50 \\
\hline Surinamese & 11.6 & 32.3 & 23,5 & 30 \\
\hline Turkish & 10.1 & 16.1 & 11,8 & 0 \\
\hline Moroccan & 15.9 & 6.5 & 11,8 & 20 \\
\hline Other & 8.7 & 9.7 & 5,9 & 0 \\
\hline Missing & 13 & 8.1 & 0 & 0 \\
\hline \multicolumn{5}{|l|}{ Education (\%) } \\
\hline No formal education/primary education & 50 & 52.6 & 37.6 & 30 \\
\hline $\begin{array}{l}\text { Lower secondary vocational education (LBO) } \\
\text { or preparatory secondary vocational education } \\
\text { (VMBO) }\end{array}$ & 20.3 & 21.1 & 25 & 30 \\
\hline \multicolumn{5}{|c|}{ How would you describe the state of your diabetes? (\%) } \\
\hline Very good & 5 & 4.4 & 33.3 & 55.6 \\
\hline Good & 36.7 & 40.4 & 46.7 & 44.4 \\
\hline Okay & 40.0 & 44.4 & 13.3 & \\
\hline Poor & 13.3 & 11.1 & & \\
\hline Very poor & 5 & 0 & & \\
\hline \multirow[t]{2}{*}{$\mathrm{HbA} 1 \mathrm{c}$ at baseline $\mathrm{mmol} / \mathrm{mol}(\mathrm{SD})$} & $62 \mathrm{mmol} / \mathrm{mol}$ & $63 \mathrm{mmol} / \mathrm{mol}$ & $60 \mathrm{mmol} / \mathrm{mol}$ & $60 \mathrm{mmol} / \mathrm{mol}$ \\
\hline & $7.80 \%(1.1)$ & $7.95 \%(1.7)$ & $7.6 \%(0.63)$ & $7.6 \%(0.88)$ \\
\hline Duration of diabetes in years (SD) & $8.36(8.0)$ & $11.65(10.2)$ & $8.23(6.2)$ & $10.3(6.2)$ \\
\hline
\end{tabular}

(eg, positive peer pressure), to effectively handle social influences that hinder self-management (eg, relatives who keep offering them sweets) and to increase the engagement and support of relatives and friends in selfmanagement (eg, by asking them to exercise together). Table 2 provides an overview of the general objectives regarding these determinants, the more specific subgoals that emerged from these objectives and their matching intervention strategies. Powerful Together with Diabetes was realised in 10 groups from August 2010 through December 2011. All groups finished both phases of the intervention, except for the Moroccan male group which ended after part 1 due to a lack of sufficient motivation.

Know Your Sugar lasted 6 weeks and consisted of six group meetings for the participants, and was based on standard diabetes education in the Netherlands. In the Netherlands, standard education for patients with type 2 diabetes consists of information and education about type 2 diabetes and self-management from the GP, GP assistant or diabetes nurse. Further, patients are advised to quit smoking, regularly exercise, lose weight when having a body mass index (BMI) $>25 \mathrm{~kg} / \mathrm{m}^{2}$ and to eat healthy for which they are referred to a dietician. ${ }^{19}$ It aimed to provide the participants with the information they needed to manage their diabetes. Though it provided the participants with the opportunity to get to know other patients, to influence each other and to exchange social support, it did not specifically target these determinants or intervene in the immediate social environments of participants. Know Your Sugar was realised in nine groups from January 2011 through November 2011. All groups finished the intervention; however, the Moroccan male group did not start due to a lack of interest among the potential participants.

Both interventions were guided by different group leaders who were matched with the participants based on ethnicity and gender. The group leaders were recruited through an advertisement and selected based on their prior experience with group-based education. The group leaders of the Dutch groups were diabetes nurses, GP assistants and physician assistants. The group leaders of the Moroccan, Turkish and Surinamese groups were lay health educators. Prior to the 
Table 2 Overview of subgoals and strategies of Powerful Together with Diabetes

\begin{tabular}{|c|c|c|}
\hline General objective & Subgoals & Intervention strategies \\
\hline $\begin{array}{l}\text { 1. Extending participants' diabetes-related social } \\
\text { networks, facilitating the exchange of social } \\
\text { support and positive social influences with group } \\
\text { members. }\end{array}$ & $\begin{array}{l}\text { Participants positively influence each other (role } \\
\text { models, positive peer pressure, positive group } \\
\text { norms). } \\
\text { Participants encourage and support each other in } \\
\text { adhering to their self-management during the } \\
\text { intervention and continue to support each other after } \\
\text { the intervention has ended (advice, helping each } \\
\text { other). } \\
\text { Participants continue to see each other after the } \\
\text { intervention and continue to do DSM-related activities } \\
\text { together (eg, exercising). }\end{array}$ & $\begin{array}{l}\text { Group meetings for patients with diabetes, phases } 1 \\
\text { and } 2 \\
\text { Participants took part in interactive games and } \\
\text { energisers (short breaks during the intervention to } \\
\text { keep the participants motivated and concentrated } \\
\text { during the rest of the programme). Energisers often } \\
\text { consisted of short exercises aimed at group bonding } \\
\text { (eg, throwing a balloon back and forth while giving } \\
\text { each other compliments) } \\
\text { Participants had to team up with someone or form } \\
\text { alliances. They were encouraged to open up to each } \\
\text { other through these games and energisers. } \\
\text { Participants were regularly invited to talk about their } \\
\text { self-management problems and to ask group } \\
\text { members for advice. To do this, the group members } \\
\text { learnt skills for giving constructive feedback. } \\
\text { In small subgroups, participants did assignments in } \\
\text { which they had to help each other (eg, adjusting } \\
\text { recipes together) to get used to giving and receiving } \\
\text { social support. } \\
\text { - Participants were encouraged to phone and/or meet } \\
\text { up with each other outside of the group meetings. } \\
\text { Group meetings for patients with diabetes, phase } 2 \\
\text { Periodic (first two weekly, then monthly) meetings } \\
\text { were held. Participants were encouraged to continue } \\
\text { seeing each other in between group meetings without } \\
\text { the group leader. }\end{array}$ \\
\hline $\begin{array}{l}\text { 2. Increasing participants' abilities to handle social } \\
\text { influences that hinder their self-management, } \\
\text { such as norms, peer pressure and temptations. }\end{array}$ & $\begin{array}{l}\text { Participants critically evaluate the impact significant } \\
\text { others have on their DSM. } \\
\text { Participants are better able to deal with social } \\
\text { influences that hinder their self-management, such as } \\
\text { peer pressure (eg, pressure to eat unhealthy foods or } \\
\text { to overeat, or negative feedback when exercising or } \\
\text { taking medications). }\end{array}$ & $\begin{array}{l}\text { Group meetings for patients with diabetes, phase } 1 \\
\text { - Group discussions were held about social situations in } \\
\text { which managing diabetes is difficult (in response to a } \\
\text { DVD, a letter of the week and of their own accord). } \\
\text { Participant practised these strategies with group } \\
\text { members during role-playing exercises. } \\
\text { Group meetings for patients with diabetes, phase } 2 \\
\text { An action plan was drawn up in which social } \\
\text { influences and dealing with social influences played } \\
\text { an important part (group meetings). Together with } \\
\text { other group members, the person with diabetes came } \\
\text { up with strategies and solutions to overcome these } \\
\text { difficulties. }\end{array}$ \\
\hline
\end{tabular}
models, positive peer pressure, positive group

adhering to their self-management during the inger continue to support each other after other).

Participants continue to see each other after the intervention and continue to do DSM-related activities together (eg, exercising).

Participants critically evaluate the impact significan thers have on their DSM.

influences that hinder their self-management, such as peer pressure (eg, pressure to eat unhealthy foods or to overeat, or negative feedback when exercising or 
Table 2 Continued

\section{General objective}

Subgoals

Intervention strategies

3. Increasing the engagement and support of the participants' significant others in self-management.
- Participants ask significant others for support.

- Participants indicate that their significant others are more involved in their self-management (providing more support or more enabling social influences).

- Participants experience more enabling social influences.

- Participants experience fewer social influences from their significant others that hinder their self-management.
Group meetings for patients with diabetes, phase 1

- Participants were encouraged to tell their significant others they have diabetes (if they did not know)

- Participants were encouraged to tell their significant others about the negative social influences and barriers they face (social network therapy).

Social network therapy session, phase 2

- Participants discussed solutions and strategies with their significant others to deal with negative social influences on self-management.

- Together with their significant others, participants agreed on an action plan in which the significant others play an active role in their self-management. In this action plan, the participant and his/her significant other(s) described the problem they would be working on and barriers and facilitators to overcome this problem. Finally, they agreed on some concrete appointments with each other to overcome this problem.

Group meetings for significant others, phases 1 and 2

- Significant others learnt more about diabetes and the important role they play in the self-management of the patient with diabetes.

- To change their norms regarding self-management tasks, the significant others critically evaluated their own lifestyles through interactive games.

- Significant others did interactive assignments in which they distinguished helpful and non-helpful behaviour with regard to self-management.

- Group discussions were held about ways to better facilitate the self-management of their relative with diabetes.

- Significant others learnt ways to ask about their relative's self-management in a friendly, supportive way (group meetings for significant others).

DSM, diabetes self-management 
intervention, the group leaders of the intervention group received an $8 \mathrm{~h}$ training and the group leaders of the control group a $2 \mathrm{~h}$ training. Both trainings focused on the implementation of the intervention. They differed in length due to the length (10 months) and complexity of Powerful Together with Diabetes.

\section{RECRUITMENT AND SAMPLING}

Qualitative in-depth, semistructured interviews with participants from the intervention and control groups and their group leaders were conducted. The aim was to interview two participants per group. Since it is hard to reach study population, the group leaders were asked to select and invite the respondents. We asked them to invite two participants that had been attending the intervention regularly and who had significant others that also participated in the intervention.

In total, 27 participants agreed to be interviewed: 17 participants from 8 intervention groups (11 Dutch, 2 Turkish women, 2 Moroccan men and 2 Surinamese) and 10 participants from 6 control groups (7 Dutch, 2 Moroccan women and 1 Surinamese). Eleven participants refused to participate. They lacked the time to participate, were on holiday or felt like they had spent enough time on the study procedures (filling out questionnaires and the physical exam). These respondents broadly reflected the wider trial population in terms of age, gender, duration of diabetes and glycaemic control (see table 1). Response among group leaders ( $n=15)$ was $100 \%$.

\section{DATA COLLECTION}

The interviews with the participants $(n=27)$ lasted 40$60 \mathrm{~min}$. The interviews with the group leaders lasted approximately 60-90 min. The intervention group leaders $(n=9)$ were interviewed twice (once during and once after the intervention) to prevent possible memory bias caused by the length of the intervention. All control group leaders $(n=6)$ were interviewed once (right after the intervention ended).

The respondents were interviewed by themselves in their first language at the respondents' homes, or in a community centre. The interviews were conducted by CV and MJEK with the help of an interpreter (Turkish interviews) or a Moroccan interviewer who had received training prior to the data collection. The Moroccan interviewer met the respondents before during other study procedures. The respondents met CV and MJEK during the observations in the intervention. Also, CV and MJEK had regular contact with the group leaders during the implementation of the intervention. The interviewers introduced themselves with little background information and emphasised they had no competing interest while conducting the interviews. They focused their introduction on wanting to evaluate the intervention and wanting to hear all (positive and negative) experiences with the intervention. The interviews were audiotaped and transcribed with the respondents' consent. A topic guide was used during all of the interviews. For the participants, topics included experiences with the intervention, changes made in selfmanagement, changes in support for and social influences on self-management and how they experienced contacts with group members (see online supplementary addendum 1). For the group leaders, topics included experiences with the intervention, changes in participants' self-management that they observed and heard from participants, barriers and facilitators, and points for improvement (see online supplementary addendum 2). After the interview, field notes were made to remember the setting and the impression the respondent made on the researcher.

\section{ANALYSIS}

Three of the researchers analysed the interviews with the participants using MAXQDA. The initial coding was done by $\mathrm{CV}$ and checked by MJEK. Consensus was reached by discussion. To preclude bias, their coding was randomly checked by a third researcher, MAH (who was blinded for intervention or control group).

We constructed an initial conceptual framework based on the theoretical assumptions of the intervention. The data were coded according to this framework. ${ }^{20}$ To determine whether the intervention's general objectives had been achieved, the interviews were searched for patterns regarding the subgoals. When a pattern was found in one group, the researchers tried to find the same pattern in the other group as well. When patterns were found only in the intervention group, they were considered to be an indication that these patterns, or differences in patterns, had been caused by the intervention Powerful Together with Diabetes.

The interviews with the group leaders were used to check and consolidate the findings that emerged from the interviews with participants through data triangulation. ${ }^{21}$ After determining relevant patterns in the interviews with participants, we checked if these findings could be confirmed by the interviews with group leaders.

\section{RESULTS}

The respondents were predominantly female, aged around 60 years who had diabetes for 8-10 years and regarded the state of their diabetes as okay-very good (table 1). Around $30 \%$ had no education, or primary education only. Two-thirds had a total house income of $<€ 1906$ per month. None of the respondents in the qualitative study considered the state of their diabetes to be poor or very poor, despite their actual HbA1c levels, which indicates that their average blood glucose levels had not been well controlled for the last weeks. In general, the respondents of the qualitative study reflected the entire study population, but had a slightly higher income, education and better self-rated diabetes- 
related health compared with the general study population. The significant others of these respondents that participated in the intervention were predominantly husbands or wives $(n=13)$. Sometimes, these respondents invited a niece, an in-law, a daughter or a neighbour $(n=5)$ as well to the intervention besides their spouses. Two respondents did not have any significant others that participated in the interventions and of two respondents, only their daughters participated.

The experienced changes in social support and social influences are described according to the general objectives of the intervention in table 3. The intervention strategies attributed to these changes are described in table 4 .

\section{Extending participants' diabetes-related social networks, facilitating the exchange of social support and positive social influences (general objective 1)}

Respondents in the intervention and control groups indicated that before the intervention, they did not talk about their diabetes with people other than their immediate social environment (spouse, children and very close friends). The reasons given for not disclosing this, even to other people with diabetes, were fear that people would only ask about their diabetes (becoming diabetes), standing out at social events, and not wanting to discuss it with strangers. Since only a few people knew about their diabetes, they could not exchange experiences with other people with diabetes and received little diabetes-related support.

After the intervention, only the intervention group reported to have influenced each other to improve their self-management, which resulted in a change in their norms for these behaviours. For example, reading food product labels together or exercising with group members made them feel more comfortable about doing this on their own (change of norms). Also, some respondents $(n=3)$ reported that they actively encouraged or were encouraged by group members to improve their self-management (eg, positive peer pressure to take medications).

And we had one man, he was so resistant.... Even so, we were finally able to get him to take his medicine... he had pills, but he didn't take them and his blood glucose just kept going up.... Then we told him, you have to do this, you have to do that, and he really listened to us. (Dutch woman, Dutch intervention group)

Furthermore, the majority of the respondents from the intervention group reported a continuous frequent exchange of emotional support. They reported that they still visit each other or plan to visit each other, exercise together or get together as a group under the (voluntary) supervision of their group leader. When they see each other, they ask about each other's well-being and experiences with diabetes.
I: And do you think you will stay in touch with group members?

R: Yes, I think so, yes. There is one woman in the E. (name of a building), I visited her once already. She is a very nice woman, I can really laugh with her (Surinamese woman, Dutch intervention group)

I don't have a spot on the camping site myself, but I visit friends of mine there. T. (group member) has a spot there too and I can drop by. That's nice. We made an appointment about that. I think that's nice (Dutch woman, Dutch intervention group)

Furthermore, both groups indicated that they phone each other, and when they run into each other on the street, they ask each other how things are going.

There is one man, I still see him in the streets because he also lives here. And there is a woman, with whom I call sometimes. To ask how things have been, how thing are now. Yes I had a very nice group (Surinamese woman, Dutch intervention group)

When we see each other, we say, "Are you still doing everything, are you taking your pills?" "Give yourself your injections on time, take your pill on time." (Turkish woman, Turkish intervention group)

However, this seemed a more dominant theme among respondents in the intervention group. In addition, only they indicated that these contacts take place on a regular basis.

What was the mechanism behind these changes in social support? How did the intervention work? From the interviews with the participants and the group leaders, it appeared that those in the intervention group were closer to each other and enjoyed the social interactions with group members more.

You could really tell each other everything.... We really became such a tight group in that respect. You don't feel embarrassed with each other, and everything was out in the open. (Dutch woman, Dutch intervention group)

Only the intervention group emphasised the pleasant atmosphere in the group and the high levels of trust between group members that facilitated the exchange of experiences and stories. More than half of the respondents mentioned that taking walks together and the 'energisers' (short breaks consisting of short exercises aimed to keep the participants motivated and concentrated during the rest of the programme) that made them laugh contributed to this atmosphere. In contrast, the control group often reported feeling no special connection to group members and used arguments that were more rational than emotional when talking about group members.

Well, you're together with people who have the same thing. And there are people who've found solutions for 
Table 3 Changes in social support and social influences reported by the participants in the intervention and control groups

\section{General objective}

1. Extending participants' diabetes-related social networks, facilitating the exchange of social support and positive social influences.

2. Increasing participants' abilities to handle socia influences that hinder their self-management, such as norms, peer pressure and temptations.
Patterns found in intervention group after participating in the intervention $(n=17)$

During the intervention:

1. Change in norms towards self-management behaviours because of social influences from group members (4 respondents from 3 Dutch groups)

2. Group members positively influenced each other by encouraging a healthy lifestyle and the use of medications (3 respondents from 2 Dutch and 1 Surinamese group)*

3. Participants exchanged stories and experiences and felt comforted by each other-emotional support (13 respondents from 5 Dutch, 1 Surinamese and 1 Turkish women group)

4. Participants exchanged advice and experiences about nutrition, exercise, taking medications, and low and high blood glucose-informational support ( 5 respondents from 4 Dutch and 1 Moroccan men group) *

5. Participants felt better because group members were worse off than they were ( 5 respondents from 5 Dutch groups)

After the intervention:

Visiting each other (4 respondents from 3 Dutch and 1

Turkish women group)

6. Exercising together (4 respondents from 2 Dutch and 1 Moroccan men group) *

7. Getting together as a group (5 respondents from 2 Dutch groups)*

8. Phoning each other (4 respondents from 2 Dutch and 1 Surinamese group)

9. Running into each other on the street (6 respondents from

3 Dutch, 1 Turkish women and 1 Moroccan men group)

1. Naming hindrances to self-management in their

immediate social environments (eg, lack of support, responsibilities towards relatives) and knowing these are barriers (13 respondents from 4 Dutch, 1 Surinamese, 1 Turkish and 1 Moroccan men group)

2. Naming facilitators to self-management in their immediate social environments of their own accord (eg, change in significant others' behaviour) (6 respondents from 3 Dutch, 1 Surinamese and 1 Moroccan men group)*

\section{Patterns found in control group after participating} in the intervention $(n=10)$

\section{During the intervention:}

Not observed*

Not observed*

Participants exchanged experiences and felt comforted by each other-emotional support (3 respondents from 1

Dutch and 1 Moroccan women group)

Participants received lots of information and solutions from group members about insulin-informational support

(3 respondents from 3 Dutch groups)

Participants felt better because group members were worse off than they were (3 respondents from 3 Dutch groups)

After the intervention:

Not observed *

Not observed*

Not observed ${ }^{*}$

Phoning each other (1 respondent from a Dutch group $)^{*}$

Running into each other on the street ( 1 respondent from a Dutch group)

Naming hindrances to self-management in their immediate social environments (eg, family responsibilities) and knowing these are barriers (1 respondent, group 9), of these: not knowing these are barriers ( 3 respondents from 2 Dutch groups)

Not observed 
Table 3 Continued

\begin{tabular}{|c|c|c|}
\hline General objective & $\begin{array}{l}\text { Patterns found in intervention group after participating } \\
\text { in the intervention }(n=17)\end{array}$ & $\begin{array}{l}\text { Patterns found in control group after participating } \\
\text { in the intervention }(n=10)\end{array}$ \\
\hline & $\begin{array}{l}\text { 3. Better able to resist food temptations at home or at parties } \\
\text { or more capable of saying no when pressured to eat too } \\
\text { much or to eat unhealthy foods ( } 7 \text { respondents from } 4 \\
\text { Dutch, } 1 \text { Surinamese and } 1 \text { Turkish women group) }{ }^{*} \\
\text { 4. Better able to handle hindering social influences on other } \\
\text { self-management domains such as smoking and taking } \\
\text { walks (4 respondents from } 4 \text { Dutch groups) }{ }^{*}\end{array}$ & $\begin{array}{l}\text { Being more serious about refusing food in social situations } \\
\text { (2 respondents from } 2 \text { Dutch groups) }\end{array}$ \\
\hline \multirow[t]{5}{*}{$\begin{array}{l}\text { 3. Increasing the engagement and support of the } \\
\text { participants' significant others in } \\
\text { self-management. }\end{array}$} & $\begin{array}{l}\text { 1. Significant others prepare healthy food for respondents } \\
\text { more often ( } 5 \text { respondents from } 3 \text { Dutch and } 1 \text { Moroccan } \\
\text { men group) }\end{array}$ & $\begin{array}{l}\text { Wife now cooks healthier meals ( } 1 \text { respondent from a } \\
\text { Dutch group) }\end{array}$ \\
\hline & $\begin{array}{l}\text { 2. Significant others help more with making healthy choices } \\
\text { when buying groceries, and do not buy things they cannot } \\
\text { have ( } 4 \text { respondents from } 2 \text { Dutch groups) }\end{array}$ & $\begin{array}{l}\text { Significant others help more with making healthy choices } \\
\text { when buying groceries ( } 1 \text { respondent from a Dutch group) }\end{array}$ \\
\hline & $\begin{array}{l}\text { 3. Relatives keep a closer watch on their food intake } \\
\text { ( } 7 \text { respondents from } 5 \text { Dutch and } 1 \text { Turkish women group) }\end{array}$ & Not observed \\
\hline & $\begin{array}{l}\text { 4. More encouragement by relatives to eat (breakfast) on } \\
\text { time, exercise and use their medications ( } 4 \text { respondents } \\
\text { from } 2 \text { Dutch, } 1 \text { Turkish women and } 1 \text { Moroccan men } \\
\text { group) }{ }^{*}\end{array}$ & Not observed \\
\hline & $\begin{array}{l}\text { 5. Significant others engage in DSM activities such as } \\
\text { eating breakfast together, taking medications together and } \\
\text { exercising ( } 5 \text { respondents from } 2 \text { Dutch, } 1 \text { Surinamese, } \\
1 \text { Turkish women and } 1 \text { Moroccan men group) }\end{array}$ & Not observed \\
\hline
\end{tabular}




\section{General objective}

1. Extending participants' diabetes-related social networks, facilitating the exchange of social support and positive social influences.

2. Increasing participants' abilities to handle social influences that hinder their self-management, such as norms, peer pressure and temptations.

3. Increasing the engagement and support of the participants' significant others in self-management.

\section{Intervention strategies during the intervention}

Group meetings for patients with diabetes, phases 1 and 2

- Participants took part in interactive games and energisers (including walking together).

- Participants were regularly invited to talk about their self-management problems and to ask group members for advice.

- Participants were encouraged to phone and/or meet up with each other outside of the group meetings.

Group meetings for patients with diabetes, phase 1

- Group discussions (tips and tricks) were held about social situations in which managing diabetes is difficult.

- Participant practised these strategies with group members during role-playing exercises.

Group meetings for patients with diabetes, phase 2

- An action plan was drawn up in which social influences and dealing with social influences played an important part (group meetings). Together with other group members, the person with diabetes came up with strategies and solutions to overcome these difficulties.

Social network therapy session, phase 2

- Together with their significant others, participants agreed on an action plan in which the significant others play an active role in their self-management.

Group meetings for significant others, phases 1 and 2
How many and which participants considered these strategies responsible for the changes they experienced? $(n=17)$

9 respondents from 3 Dutch, 1 Surinamese and 1 Turkish women group

8 respondents from 4 Dutch groups

1 respondent from a Surinamese group

5 respondents from 3 Dutch groups

4 respondents from 2 Dutch, 1 Surinamese and 1 Turkish women group

6 respondents from 3 Dutch and 1 Turkish women group

5 respondents from 3 Dutch and 1 Turkish women group

10 respondents from 5 Dutch, 1 Turkish women and 1 Moroccan men group 
certain things, and then I think, right, this is where you come into contact with people like this. (Dutch man, Dutch control group)

Finally, we observed an exchange of informational support in both groups: participants shared information and advice about diabetes, nutrition, medications and blood glucose levels. Participants in both groups also liked to compare themselves with group members who were worse off. They were comforted by feeling they were not the only one with health problems and difficulties.

So if you don't feel so well yourself sometimes, then you think, well, don't complain, because you're not the only one who feels this way. That's great, that's really great, that you know that about each other. (Dutch woman, Dutch intervention group)

Almost half of the respondents told that exchanging support, tips and tricks was stimulated during the meetings. They indicated that they were invited to discuss selfmanagement problems and to advice others who were having difficulties with self-management behaviours.

\section{Increasing participants' abilities to handle social} influences that hinder their self-management, such as norms, peer pressure and temptations (general objective 2)

Before the intervention, most respondents in both groups were aware that they and their significant others shared the same unhealthy lifestyle. For most respondents, self-management meant behaving differently from their significant others. Peer pressure to eat too much or to eat unhealthy foods at social events was mentioned most often as this Moroccan woman (control group) describes:

'Yes, but eat-you haven't, you haven't had anything to eat yet! Eat!" ... Then I say, sorry, I just ate. "Yes, but we invited you, so why did you eat at home?" ... You're just trying to show them that you're normal, too. (Moroccan woman, Moroccan control group)

The respondents also mentioned being confronted with food temptations, and to find it hard to eat on time at parties. Although some respondents dealt adequately with these social influences, most saw them as just the way things were or impossible to change.

After the intervention, the intervention group seemed better able to critically evaluate the impact of their social environments on their self-management. Both groups reported social influences from their significant others that hinder self-management, such as relatives who keep offering snacks or refuse to go on walks together, being lonely and too many family responsibilities.

He [husband] just eats and eats. And then he says, "What about you? Don't you want anything?" I say no. "Don't be ridiculous!" So I say, no, G. [name husband], I say, I promised I'd lose weight, remember? Well, I'm doing just fine. You heard him, didn't you, when he asked me, "Do you want a biscuit?" No. "Do you want a biscuit?" No. (Dutch woman, Dutch intervention group)

However, in contrast with the intervention group, most respondents in the control group did not seem to be aware that these influences hindered their self-management.

I: Do you (respondent and his family) also take each other's needs into account?

$\mathrm{R}$ : Yes, but not really because there are more people in this household and they also need to be cooked for and I also come home at irregular hours sometimes.

Moreover, the intervention group also seemed to be aware of positive social influences on their selfmanagement such as relatives who eat wholegrain rice without complaining. The intervention group also seemed better able to handle social influences that hinder their self-management. Both groups reported that they are now better able to resist temptations and pressure to eat unhealthy foods than before the intervention. However, only the intervention group named specific strategies they used in these situations, such as things they would say or arguments they would use.

In our family, it's the custom to set everything down in front of you: "Take, take, take, have some of this, too, and some of that, too"... So I'll say something like, "I took a class, and they told me I can't have that. That's why I'm not having any." (Turkish woman, Turkish intervention group)

These strategies were not observed in the control group.

Sometimes you're with a group of people and you say, no, I won't have anything, and then they start talking crap to you, things like, "Just have something for once, will you?" and then you have to stay strong, so to speak.... Yes, then I have to say no.... Yes, you have to go about things a little differently, it's not easy, but it's what you have to do. I: So how do you do that, then? R: Well, I just don't do it. (Dutch man, Dutch control group)

The results thus indicate that due to the intervention, the participants in the intervention group were better able to handle social influences that would hinder them in their self-management. What elements in the intervention accounted for this effect?

A quarter of the respondents in the intervention group attributed these changes to the skills they learnt in the role-playing exercises in which they practised being at a party and refusing food being offered or things they would say if someone asked them why they did not eat. 
No, I told them, I'm taking a class and that's where I learned everything.... Sometimes they say, have a little, it's so good. No, you don't have to force me, I'll have some if I want. And you shouldn't force it on me (direct quote from roleplaying exercise). Yes, because we learned that, too.... Why do you offer me things? and so on. (Surinamese woman, Surinamese intervention group)

One-third of the respondents mentioned the feedback and tips and tricks they received and shared with group leaders and members.

So I learned, make sure you're not hungry (at a party) and drink a lot of water. If I am tempted I take a little sip of water.

\section{I: Does that help?}

R: It does help, because then I am distracted (Dutch woman, Dutch intervention group)

In addition, the action plan that participants made with their relatives helped them to improve their selfmanagement. This was also the case for behaviour other than food intake, for which only the intervention group reported being better able to handle social influences on these behaviours. Examples included smoking less even though their relatives discouraged them from doing this, and going out for a walk even if their spouse did not want to. When talking about these changes, one-third of all respondents said they felt supported by the action plan they made with their relatives.

I try to [exercise more]. My wife is having a really hard time with it right now. She tries to, but um... Sometimes she doesn't want to leave the house. Sometimes we just have to um... agree to do things (action plan) and then we do get out the door. Then we do it. (Dutch man, Dutch intervention group)

\section{Increasing the engagement and support of the} participants' significant others in self-management (general objective 3)

Before the intervention, most respondents of Dutch origin felt their diabetes was their own responsibility and seemed unaware that more support from significant others would make self-management easier. Only the Moroccan, Turkish and Surinamese respondents believed more support would make self-management easier and regretted not receiving more support.

At the start of the intervention, the participants and the group leaders indicated that, although the participants' relatives understood the importance of taking medications, they knew little about physical activity, a healthy diet or monitoring of blood glucose. Furthermore, most relatives seemed unaware of their own role in self-management or felt that diabetes was the patient's responsibility only. Some relatives wanted to offer support but did not know how or felt that their help would not be accepted.
After the intervention, the intervention and control groups experienced more instrumental and appraisal support from their relatives. Their relatives prepare healthier food for them more often and help them make healthier choices when shopping for groceries. However, only the intervention group specified what their relatives changed about their cooking (less oil and salt, more vegetables).

Well, cooking, my wife used to use a lot of salt, but she doesn't use much anymore.... And also fats, oil, she uses less oil now. (Moroccan man, Moroccan intervention group)

The intervention group also seemed to make deliberate choices about what and what not to buy when shopping.

Once in a while I'll have some crisps, but we don't buy crisps at all anymore. If we eat them, we eat them at someone else's place. My wife even said so last week [when they were visiting someone], well, P., have some crisps here, because we don't have them at home anymore. (Dutch man, Dutch intervention group)

And we also had a dietician [during the intervention], and she went to the store with us and told us what we had to watch for. That might sound strange, but since then I always read things when I'm in the supermarket [laughter]. And my husband does it too. To see if it's actually, uh... you know. (Surinamese woman, Dutch intervention group)

The control group only added some healthy items to what they bought.

If we go grocery shopping now, we always get a head of lettuce, a cucumber, and a tomato. We never used to do that. (Dutch man, Dutch control group)

In addition, only the intervention group experienced more enabling social influences in their social environments since the intervention. Their relatives watch their food intake more closely and encourage them to eat breakfast (on time), exercise and use medications correctly.

For example, you have a dessert, and then you have another one: "Mama, that's bad for you. You eat a loteat a little less." (Turkish woman, Turkish intervention group)

If I don't feel like going to exercise class, "You really should, Mama, it's good for your body." (Surinamese woman, Surinamese intervention group)

Also, since the intervention, the intervention group engages in self-management behaviours together with relatives (eg, eating breakfast, exercising or taking their medications together). This was not observed in the 
control group. This helps the respondents to maintain these activities.

R: 'I started to exercise.' I: 'How did you do that?' R: 'Well, he (husband) and I joined a sport club [...] Sometimes we walk together, but we also joined a.. what is it called? Fitness....we do fitness now.' I: 'And how do you maintain exercising?' R: 'We do it together now, you know, my husband and me.' (Surinamese women, Dutch intervention group)

These results indicate that the intervention promoted the integration of the social network of the participants in their diabetes self-management behaviour. Which elements of the intervention accounted for this effect? The majority of the respondents attributed these changes to the family meetings and to the group leader, who talked with their relatives about making changes. They did not specify which elements of these meetings contributed to these changes. One-third of the respondents mentioned the action plans they made together with their relatives.

My goal [in the action plan] was to have breakfast in the morning. That's something I never did.... R [husband] and my grandmother [who lives in the same house], she also has to eat in the morning, and then we started eating in the morning (Dutch woman, Dutch intervention group)

\section{DISCUSSION}

The intervention group was influenced by other group members to change their norms towards selfmanagement, and their self-management itself. Also, the exchange of emotional support continued after the intervention ended. Intervention strategies that contributed to these changes were practising self-management with and encouragement from group members, walking together and energisers that created a pleasant atmosphere and high levels of trust in the groups. The intervention group seemed better able to recognise and prepared for social influences on self-management and better able to deal with more diverse social influences on self-management. The skills learnt through roleplaying exercises, as well as receiving feedback from group members and making an action plan with relatives contributed to these changes. Finally, only the intervention group reported that relatives watch them more closely, encourage them to perform self-management behaviours and engage in these behaviours with them. Making an action plan together, having relatives participate in family meetings and listening to group leaders contributed to these changes.

\section{Strengths and limitations}

In this underexplored area, this study provides an exploration of the intervention strategies underlying the effects of a group-based intervention. However, given the qualitative design, this study does not allow a firm conclusion about the causality of the observed changes in relation to the intervention. The positive results do, however, justify the value of developing a randomised controlled trial to quantitatively test the effect of the intervention Powerful Together with Diabetes.

In addition, this study only reports on intervention strategies that actually contributed to the changes in social support and social influences regarding the participants' self-management. This might suggest bias because of an assumption that the intervention was effective. During the interviews, the participants found it challenging to link changes in social support for and social influences on their self-management to specific intervention strategies. Although they were able to mention practical aspects of the intervention that did not work (such as that they did not identify with the multicultural character of an educational video), they did not identify intervention strategies that did not lead to a change in determinants. This is likely to be caused by the abstract nature of this type of questions. In hindsight, knowing that we have not been able to test the effectiveness quantitatively, this study could have been strengthened by studying intervention strategies that did not contribute to changes in social support for and social influences on self-management through other qualitative research methods as well.

Also, the respondents of the qualitative study have a slightly higher income, education and better self-rated diabetes-related health compared with the general study population. However, these differences are small and the respondents of the qualitative study can still be considered socioeconomically deprived despite these differences. Therefore, we have no reason to assume that the intervention strategies might have worked better or worse among this population than among the entire study population, thus biasing the results of this study.

Furthermore, the respondents were interviewed right after the end of the intervention which gives no indication of long-term intervention effects. Also, the participants' accounts might be subjected to recall bias, because of the length of the intervention. However, in both groups, only one respondent reported difficulties with remembering the intervention in detail. Furthermore, the majority of the results found in the interviews with the participants were verified by the interviews with group leaders and did not lead to other conclusions.

In our intervention, emotional support, promoted by a pleasant atmosphere in the group, appeared to be crucial for improving diabetes self-management. Interestingly, the participants received emotional support primarily from group members rather than from relatives or friends. Other studies have also shown that peer support is important for patients with diabetes because it gives them the opportunity to share similar experiences and specific concerns. ${ }^{22-24}$ Relatives might not be able to provide emotional support because they do not have diabetes themselves or experience the disease differently. This is confirmed by other studies. 
Spouses and relatives of patients might have different concerns and ideas about self-management than the patients. $^{25}$ Carter-Edwards shows that among African-American women with type 2 diabetes, relatives care but often do not understand, which is why these women do not get the support they need. ${ }^{26}$

Practising difficult situations together through role playing and then giving each other feedback appeared to be a promising element of the intervention. This might have made the participants more confident that they could implement these strategies in their own social environments. This is in accordance with other studies that show that preparing coping plans is necessary for making and maintaining lifestyle changes. ${ }^{27}$ In addition, focusing on behaviour-related tasks and feedback is one of the features that seems successful in interventions that try to improve self-management among socioeconomically deprived patients. ${ }^{28}$

Many tasks related to self-management take place in interaction with relatives, and the involvement of spouses in particular can be an important source of practical support. However, relatives can also function as a source of stress and interference when they undermine rather than facilitate self-management. ${ }^{29}$ Therefore, although actively involving relatives is likely to improve self-management behaviours, to our knowledge, there are no studies that discuss the best ways to involve relatives of patients in socioeconomically deprived neighbourhoods in these behaviours. In this intervention, making an action plan together and implementing and optimising it over time seemed to increase communication about self-management, and with this came awareness of the relatives' specific role in selfmanagement. The action plan was very specific and made it easier for the participants and their relatives to determine shared goals and make actual appointments about self-management together. This increased the involvement of relatives in self-management, for example, they are now paying more attention to self-management, encourage and engage more in self-management behaviours.

\section{CONCLUSIONS}

This group-based intervention 'Powerful Together with Diabetes' seems to increase social support and diminish hindering social influences on self-management in socioeconomically deprived patients with type 2 diabetes. Promising elements of the intervention were skills training and providing feedback using role-playing exercises in group sessions with patients, as well as the involvement of patients' significant others in selfmanagement tasks, and actively involving them in making an action plan for self-management. These positive results justify the value of further evaluating the effectiveness of the intervention in a larger sample.

\section{Author affiliations}

${ }^{1}$ Department of Public Health, Academic Medical Center, University of Amsterdam, Amsterdam, The Netherlands
${ }^{2}$ Department of General Practice, EMGO Institute VU University Medical Center, Amsterdam, The Netherlands

${ }^{3}$ Department of Public Health, The Hague's Public Health Department, The Hague, The Netherlands

${ }^{4}$ Department of Public Health, Leiden University Medical Center, Leiden, The Netherlands

Acknowledgements The authors would like to thank Colleen Higgins for editing the final draft of this paper.

Contributors CV coordinated the study, developed the intervention, constructed the design and drafted the manuscript. KS and VN developed the study, constructed the design and revised the manuscript. GN, PJMU and BJCM participated in the design of the study and revised the manuscript. MJEK coordinated part of the study and participated in the analyses of the study. MAH participated in the analyses of the study. All authors read and approved the final manuscript.

Funding This work was supported by the Netherlands Organisation for Health Research and Development (ZonMw) (project number ZonMw 76500003).

Competing interests None declared.

Ethics approval Medical Ethics Committee of the Academic Medical Center (AMC) in Amsterdam.

Provenance and peer review Not commissioned; externally peer reviewed.

Data sharing statement Patient-level data (qualitative in-depth interviews) are available from the corresponding author. Informed consent for data sharing was not obtained, but the presented data are anonymised and risk of identification is very low.

Open Access This is an Open Access article distributed in accordance with the Creative Commons Attribution Non Commercial (CC BY-NC 4.0) license, which permits others to distribute, remix, adapt, build upon this work noncommercially, and license their derivative works on different terms, provided the original work is properly cited and the use is non-commercial. See: http:// creativecommons.org/licenses/by-nc/4.0/

\section{REFERENCES}

1. Bachmann M, Eachus J, Hopper C, et al. Socio-economic inequalities in diabetes complications, control, attitudes and health service use: a cross-sectional study. Diabet Med 2003;20:921-9.

2. Connolly V, Unwin N, Sherriff P, et al. Diabetes prevalence and socioeconomic status: a population based study showing increased prevalence of type 2 diabetes mellitus in deprived areas. J Epidemiol Community Health 2000;54:173-7.

3. Espelt A, Borrell C, Roskam AJ, et al. Socioeconomic inequalities in diabetes mellitus across Europe at the beginning of the 21 st century. Diabetologia 2008;51:1971-9.

4. Goldman DP, Smith JP. Can patient self-management help explain the SES health gradient? Proc Natl Acad Sci U S A 2002;99:10929-34.

5. Onwudiwe NC, Mullins CD, Winston RA, et al. Barriers to self-management of diabetes: a qualitative study among low-income minority diabetics. Ethn Dis 2011;21:27-32.

6. Wolff K, Cavanaugh K, Malone R, et al. The diabetes literacy and numeracy education toolkit (DLNET) materials to facilitate diabetes education and management in patients with low literacy and numeracy skills. Diabetes Educ 2009;35:233-45.

7. Schillinger D, Grumbach K, Piette J, et al. Association of health literacy with diabetes outcomes. JAMA 2002;288:475-82.

8. Gallant MP. The influence of social support on chronic illness self-management: a review and directions for research. Health Educ Behav 2003;30:170-95.

9. Glanz K, Rimer BK, Viswanath K. Health behavior and health education: theory, research, and practice. John Wiley \& Sons, 2008.

10. Riley KM, Glasgow RE, Eakin EG. Resources for health: a social-ecological intervention for supporting self-management of chronic conditions. J Health Psychol 2001;6:693-705.

11. Tillotson LM, Smith MS. Locus of control, social support, and adherence to the diabetes regimen. Diabetes Educ 1996;22:133-9.

12. Field J. Social capital. 2nd edn. London and New York: Routledge Taylor \& Francis Group, 2008.

13. Lawrence W, Skinner C, Haslam C, et al. Why women of lower educational attainment struggle to make healthier food choices: the 
importance of psychological and social factors. Psychol Health 2009;24:1003-20.

14. Eakin EG, Bull SS, Glasgow RE, et al. Reaching those most in need: a review of diabetes self-management interventions in disadvantaged populations. Diabetes Metab Res Rev 2002;18:26-35.

15. Ding EL, Prescott MR, Watson KT, et al. Microclinic social network lifestyle intervention for weight loss and obesity management: a 10-month randomized controlled trial. Circulation 2013;127 (Supplement):A009.

16. Shaya FT, Chirikov VV, Howard D, et al. Effect of social networks intervention in type 2 diabetes: a partial randomised study. J Epidemiol Community Health 2014;68:326-32.

17. Vissenberg C, Nierkens V, Uitewaal PJ, et al. The DISC (Diabetes in Social Context) study-evaluation of a culturally sensitive social network intervention for diabetic patients in lower socioeconomic groups: a study protocol. BMC Public Health 2012;12:199.

18. Permentier M, Kullberg J, van Noije L. Werk aan de wijk. Een quasi-experimentele evaluatie van het krachtwijkenbeleid. The Haag: Sociaal en Cultureel Planbureau, 2013.

19. Rutten G, De Grauw W, Nijpels G, et al. NHG-Standaard Diabetes mellitus type 2. NHG-Standaarden 2009. Springer, 2009:160-91.

20. Gale NK, Heath G, Cameron E, et al. Using the framework method for the analysis of qualitative data in multi-disciplinary health research. BMC Med Res Methodol 2013;13:117.
21. Fossey E, Harvey C, McDermott F, et al. Understanding and evaluating qualitative research ${ }^{*}$. Aust N Z J Psychiatry 2002;36:717-32.

22. van der Ven N. Psychosocial group interventions in diabetes care. Diab Spectr 2003;16:88-95.

23. Olsson CA, Boyce MF, Toumbourou JW, et al. The role of peer support in facilitating psychosocial adjustment to chronic illness in adolescence. Clin Child Psychol Psychiatry 2005;10:78-87.

24. Joseph DH, Griffin M, Hall RF, et al. Peer coaching: an intervention for individuals struggling with diabetes. Diabetes Educ 2001;27:703-10.

25. Peyrot M, McMurry Jr JF, Hedges R. Marital adjustment to adult diabetes: interpersonal congruence and spouse satisfaction. J Marriage Fam 1988;50:363-76.

26. Carter-Edwards L, Skelly AH, Cagle CS, et al. "They care but Don't understand": family support of African American women with type 2 diabetes. Diabetes Educ 2003;30:493-501.

27. Hankonen N, Absetz P, Haukkala A, et al. Socioeconomic status and psychosocial mechanisms of lifestyle change in a type 2 diabetes prevention trial. Ann Behav Med 2009;38:160-5.

28. Glazier RH, Bajcar J, Kennie NR, et al. A systematic review of interventions to improve diabetes care in socially disadvantaged populations. Diabetes Care 2006;29:1675-88.

29. Henry SL, Rook KS, Stephens MAP, et al. Spousal undermining of older diabetic patients' disease management. $J$ Health Psychol 2013;18:1550-61 